\title{
Augev Method and an Innovative Use of Vocal Spectroscopy in Evaluating and Monitoring the Rehabilitation Path of Subjects Showing Severe Communication Pathologies
}

\author{
Antonia Campanella1, Fabio Manca ${ }^{2}$, Claudia Marin², Vittoria Bosna ${ }^{2}$, Ignazio Salonna3, \\ Maria Galatola ${ }^{1}$, Elita Anna Sabella ${ }^{2}$ \\ ${ }^{1}$ Centri La comunicazione s.r.l.u., Bari, Italy \\ ${ }^{2}$ Educational Sciences, Psychology, Communication, University of Bari Aldo Moro, Bari, Italy \\ ${ }^{3}$ School of Medicine: Basic Medical Sciences, Neuroscience and Sense Organs, University of Bari Aldo Moro, Bari, Italy \\ Email: antoniacampanella.augev@gmail.com, fabio.manca@uniba.it, claudia.marin@uniba.it, vittoria.bosna@uniba.it, \\ ignazio.salnna@uniba.it,marisa.galatola@gmail.com, elita.sabella@uniba.it
}

\begin{abstract}
How to cite this paper: Campanella, A., Manca, F., Marin, C., Bosna, V., Salonna, I., Galatola, M. and Sabella, E.A. (2019) Augev Method and an Innovative Use of Vocal Spectroscopy in Evaluating and Monitoring the Rehabilitation Path of Subjects Showing Severe Communication Pathologies. International Journal of Clinical Medicine, 10, 27-52.
\end{abstract}

https://doi.org/10.4236/ijcm.2019.102004

Received: January 13, 2019

Accepted: February 12, 2019

Published: February 15, 2019

\section{Copyright $\odot 2019$ by author(s) and} Scientific Research Publishing Inc. This work is licensed under the Creative Commons Attribution International License (CC BY 4.0).

http://creativecommons.org/licenses/by/4.0/

c) (†) Open Access

\begin{abstract}
A strongly connotative element of developmental disorders (DS) is the total or partial impairment of verbal communication and, more generally, of social interaction. The method of Vocal-verb self-management (Augev) is a systemic organicistic method able to intervene in problems regarding verbal, spoken and written language development successfully. This study intends to demonstrate that it is possible to objectify these progresses through a spectrographic examination of vocal signals, which detects voice phonetic-acoustic parameters. This survey allows an objective evaluation of how effective an educational-rehabilitation intervention is. This study was performed on a population of 40 subjects (34 males and 6 females) diagnosed with developmental disorders (DS), specifically with a diagnosis of the autism spectrum disorders according to the DSM-5. The 40 subjects were treated in "la Comunicazione" centers, whose headquarters are near Bari, Brindisi and Rome. The results demonstrate a statistical significance in a correlation among the observed variables: supervisory status, attention, general dynamic coordination, understanding and execution of orders, performing simple unshielded rhythmic beats, word rhythm, oral praxies, phono-articulatory praxies, pronunciation of vowels, execution of graphemes, visual perception, acoustic perception, proprioceptive sensitivity, selective attention, short-term memory, segmental coordination, performance of simple rhythmic beatings, word rhythm, voice setting, intonation of sounds within a fifth, vowel pronunciation, consonant pronunciation, graphematic decoding, syllabic decoding, pronunciation of caudate syllables, coding of final syllable consonant, lexical
\end{abstract}


decoding, phoneme-grapheme conversion, homographic grapheme decoding, homogeneous grapheme decoding, graphic stroke.

\section{Keywords}

Re-Educational Method, Learning Difficulties, Developmental Disorders, Vocal Spectroscopy

\section{Introduction}

The method of Vocal-Verb Self-management (AUGEV) [1] is a systemic organic-educational and re-educational method aimed at overcoming interferences in verb-interplay communication [2] through the development of neuro-psycho-physiological learning bases [3]. The vocal verb adjective indicates a twofold purpose of this method that is aimed on one hand at promoting verbal structure learning, on the other at perceiving and using verbal language acoustic qualities [4]. This method is therefore a re-education path aimed at subjects with linguistic and communication difficulties of different degrees [5]: subjects with problems of phono-articulatory setting, subjects with pathologies of verbal-social-relational communication (autism disorders, aphasia, dyspraxia [6], attention deficit and hyperactivity disorder) and subjects with learning difficulties (dyslexia, dysgraphy, dysorthography, dyscalculism).

In subjects with serious problems of verbal communication, particularly in cases of language absence, the gap in regular and physiological development becomes increasingly pronounced with age progress, as it emerges:

1) a lack or partial use and training of pneumophonic coordination functions in expiratory phase [7];

2) an altered resonance of laryngeal sound in supraglottic cavities (pharyngeal, mesopharynx, nasopharynx) [8];

3) an altered sensation and perception of personal and others' vocal productions with following inactivation of phonatory feedbacks [9], which are essential to develop quality and quantitative voice self-control, to improve phonatory emissions and therefore to produce correctly the mnemonic process;

4) an inability to discriminate and "finalize" sounds coming from the surrounding environment.

These serious obstacles, therefore, in being aware of phonatory control mechanisms, in discriminating voices as well as one's voice above all, leave out the subject from speakers' reality [10], towards which he/she shows even greater inattention and lack of interest [11].

The main purpose of this method is to acquire spoken and written communication through developing physiological and neuro-psychological learning assumptions.

Based on neural interconnections among various cortical areas [3], AUGEV method uses simultaneous, integrated, interacting and interconnected multiple 
stimulations of an esteroceptive (hearing-view), proprioceptive (muscle-taouch) and endoceptive (mucosa) nature, organized in 4 operating paths called: audio-visual-touch-speech, phono-kinesthesia and phono-linguistics, which find their highest enhancement in prosodic read-writing, electively aimed at pursuing an adequate learning process goal [12].

The method aims at helping a person to realize oneself as an harmonious unit which includes physical-motor and psycho-intellectual elements.

In particular, the method is recognized in three fundamental assumptions that characterize different rehabilitative actions:

1) The intrinsic connection between word and movement. In fact, it enhances the body as a medium of verbal learning based on the principle that structural elements of spoken language can be taught by linking vocal emissions to body movements [13] so that they can be more easily internalized to achieve smoother and more verbal expressive performances. Body mediation, which consists in functionally connecting verbal phonetic structures to body expressions and rhythms, is therefore the main didactic communication means through exercises in which a constant association is established among postures, gestures and voice. Motor acts have been organized with great precision, respecting some founding principles of mechanical physics and in particular static and dynamics [14] applied to human body [15].

2) The connection existing between spoken language and music [16], then verbal expression musicality and its corresponding expressiveness in music [17]. Since cortical areas assigned to functions of acoustic memory, and in particular those which preside over the processing of verbal solicitations, are sensitive to musical stimulations [18], AUGEV method includes exercises based on presentating sound solicitations as in a sung form, therefore exercises of listening and reproduction of melodic vocal sequences exemplifying the most recurrent rhythmical and tonal structures of spoken language [19]. Verbal messages are also presented and formulated in association with appropriate bodily movements, so that sound events and body gestures are analogically related to each other and mutually reinforcing.

3) The association of sounds and movements with simple graphic representations and immediately accessible. These are functionally important since they spatialize sounds [20] so that a subject can visualize their fundamental parameters: frequency (whose perceptual correlation is the height), duration (or emission time) and amplitude (whose perceptive correlation is intensity) [21].

Thanks to all these elements, a subject can gradually and physiologically [22] [23] acquire language basic structures [24] (words and their sentence combinations) and dynamics that regulate it (syntax and prosody) [25] in order to have access to its fruition and interpersonal communication use [26].

Peculiarities of systemic the organicistic method "Verb-vocal self-management"

A typical characteristic of this method, denoting its absolute innovation and effectiveness, is the punctual and precise perceptual enhancement carried out 

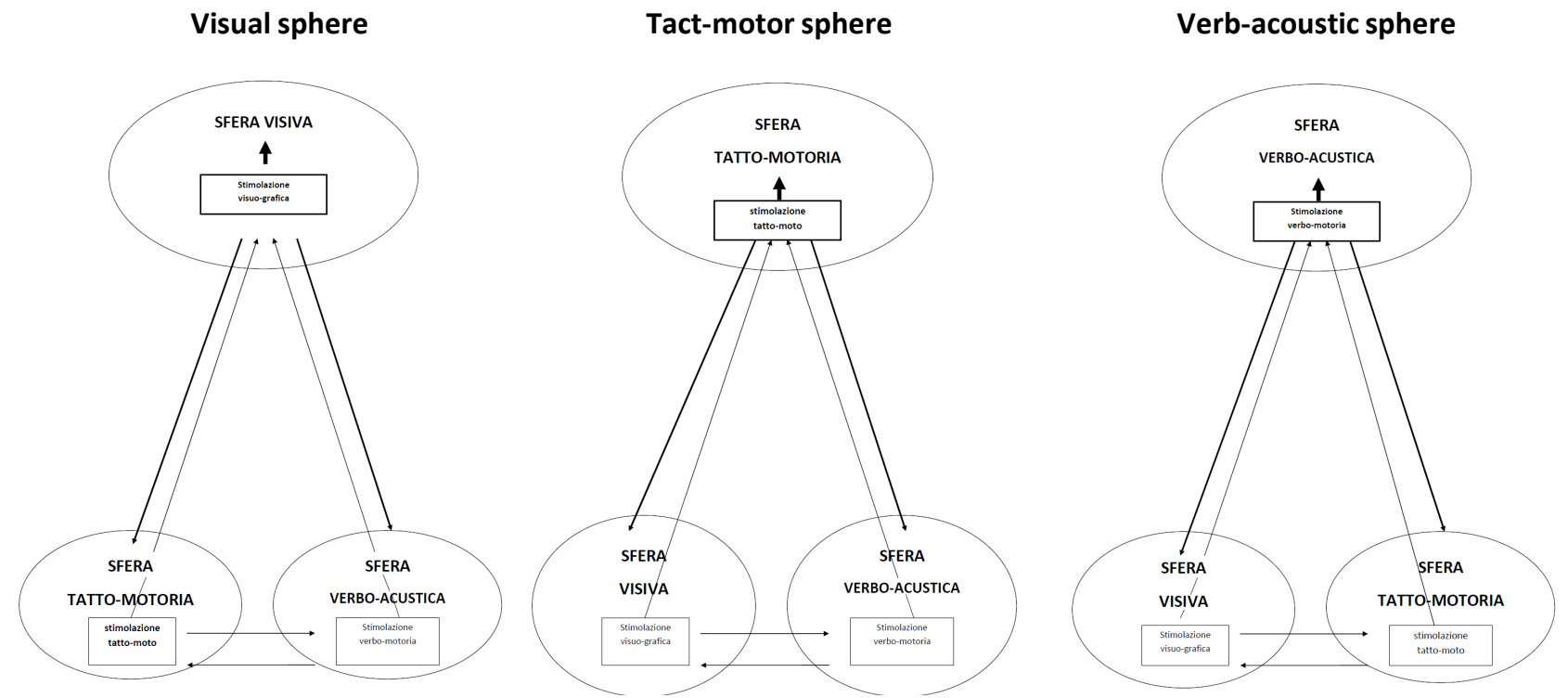

Figure 1. Coordinated cooperation of the learning spheres. 
(Synchresis)

Synchresis stimulates the attention to simple and global sensory-perceptive information (auditory, visual, tactile and motor).

These stimulations leave weak and generic perceptive traces [33].

During this phase, a subject is guided by the operator who favors initiation of cognitive processes (attention, perception, memory, thought and language) [34] through coordinated and simultaneous multiple stimulations that exploit a mechanism of repetitiveness to activate a sense-perceptive feedback process that allows the subject to create and store correct and basic motor and verb-motor patterns.

(First Analysis)

After activating cognitive development which is globally realized by syncretic phase, a subject is analytically helped to achieve conscious and selective learning [35], a fundamental step to acquire knowledge, to use them at the right time and to conquer the others independently [36].

In this phase, it is possible to evaluate the activation of important perceptive areas: visual, acoustic and proprioceptive sensitivity [3].

The subject is no longer guided as in syncresis, but only helped by the operator who sets himself up as a model: a selective attention gradually activated by analysis activities makes it possible to start an imitative capacity.

\section{Method}

This research work is a systematic study on case histories that aims at analyzing the effects of applying AUGEV method, which was adopted at logopsicopedagogical centers "La Comunicazione" in the headquarters of Bitritto (Bari), Brindisi and Rome between 2002 and 2017. The study involved 40 subjects, 34 males and 6 females, whose age was between 2 and 21 years with a diagnosis being included into developmental disorders (DS), specifically with a diagnosis of the autism spectrum disorders according to the DSM-5 [29]. Personal data, in particular those on health, were treated in accordance with the responsibilities established by the regulations of the good clinical practice (legislative decree $211 / 2003)$. At the time of taking charge of those subjects at the center, we take a look at the clinical analysis performed by a specialist physician (neurologist, audiologist, phoniatrist, etc.) and then we proceed to functionally evaluating individual learning areas carried out by a multidisciplinary team, to start then the operational phase of applying AUGEV method. Based on the emerged results, an initial assessment of development degree of various learning areas is made and a targeted and personalized omnidirectional systemic rehabilitative educational intervention is developed. After a treatment period, patients are re-evaluated with the same diagnostic protocol performed at the beginning. The evaluation at the beginning and during subsequent checks is noted in medical records.

Clinical records of subjects with autism and autism specimens were analyzed in order to identify any progress, resulting from applying AUGEV method in 
different learning areas: cognitive-behavioral, motor and linguistic.

In particular, data was inserted and processed using SPSS software (Statistical Package for Social Science) to calculate univariate descriptive statistics by frequency distribution and the bivariate ones by contingency tables. In order to evaluate the meaning of relationship in double entry tables, $\chi^{2}$ test was adopted, taking into consideration only those tables for which $\mathrm{p}$ value was lower than 0.05 .

It is essential to specify that in this study only data related to Syncresis phase and those related to the initial part of analytical phase were examined, called actually First Analysis to simplify. A following study will socialize the data concerning completion of educational-rehabilitation process implemented by Augev method.

However, the most significant analysis of data has concerned objective surveys carried out through vocal spectrographic examination.

Actually, physical-acoustic parameters of each subject's voice were found with a computerized sonograph: Fundamental Frequency $\left(\mathrm{F}_{0}\right)$, First and Second Forming $\left(\mathrm{F}_{1}\right.$ and $\left.\mathrm{F}_{2}\right)$, Duration $(\mathrm{T})$ and Phonatory Energy $(\mathrm{E})$.

Monitoring was performed by comparing "captured" values during spectrographic recording with a standardized reference range which shows average values classified by age and sex.

It should be noted that frequencies $\left(\mathrm{F}_{0}, \mathrm{~F}_{1}, \mathrm{~F}_{2}\right)$ are measured in $\operatorname{Hertz}(\mathrm{Hz})$, Emission time in seconds (sec) and Phonatory energy in decibel (dB).

Method operating modes: Syncresis and First Analysis

Syncretic activities proposed in motor area involve the body as a whole and the subject, who is initially guided, experiences all space "dimensions" and individual movement succession over time.

In particular, 8 exercises of general dynamic coordination (summarized by graphical symbols) are provided during synchresis phase, which create tension states and large muscular district relaxation which facilitate the emission of vocal sounds associated with them [37].

The subject performs movements with the arms by moving them upwards, downwards or sideways, and makes coordinated leg movements (bends or lateral displacements) and listens to vocalic emissions spatialized by those motor acts (high, low, long, short sound, intense, weak). Sound stimulations are produced by an instrument and therefore "vocalized" by the operator. They are characterized by simple iterant sound combinations presented with the aim of improving acoustic sensitivity towards sounds in order to improve the ability to adapt to models [38].

By doing an activity that acts as a bridge between motor and linguistic areas, a recognition of rhythmic differences among words with different tonic accent [39] is also started by simple finger strokes on a support surface: very simple words are obviously proposed in synchresis, such as monosyllables (you, there, no, etc.) or bisyllables (mother, bread, ball, etc. or father, so, why, etc.) 
In linguistic area, a subject is trained to listen to vowel sounds and is helped in their production.

These fundamental sounds during language practice are "hooked" even better at a perceptive level, thanks to their graphic trace (writing), which the subject begins to perform with the operator's help. The movements performed to execute each grapheme are sonorized by the operator who proactively highlights its specificities: its voice will therefore go upwards, downwards or it remains constant by being coordinated with the graphic section being created. Thus, the subject begins to familiarize with main melodic movements of linguistic expressions, that is, the interrogative, exclamatory, affirmative and suspensive ones [40].

A perceptual coordination that comes to be realized in each activity has an immediate implication in the cognitive-behavioral area [41]: a subject begins to feel capable of performing required tasks and then shows always greater interest towards them, gradually eliminating any behavioral intemperance that signaled an inadequacy perception [42].

Analytical phase activities proposed in motor area aim to achieve a segmental coordination, which is essential for a subject to experience dynamic potentials of body individual parts.

Exercises are performed in different postures and include movements aimed at indicating pre-established body points; as in syncresis, motor acts are combined with phonatory emissions that harmonize with body movements. The same sound concatenations are also spatialized by graphic scales that a subject has to perform with fingers.

In this phase, the acquisition of three fundamental sound parameters takes progressively place: the frequency perceived as sound height (acute and severe sounds), the emission time and the amplitude whose perceptive correlation is intensity (loud and weak sounds) [43], only generically presented in synchresis. In this way, high and low sounds can be discriminated, as well as long ones from short ones and strong ones from weak ones, which is a fundamental prerequisite for enjoying fundamental discourse elements such as intonation, duration, rhythm and accentuation in all its degrees.

Analytical phase includes a considerable number of exercises which, presented gradually and adapted to a subject's ability, aim at steadily acquiring spatial and temporal patterns, as well as obvious somatognosic ones which are essential pillars of learning in all of its form [44].

Sequences of rhythmic beats already presented in syncresis are proposed in a shielded mode so as to stimulate and simultaneously evaluate acoustic attention and the beginning of rhythmic-motor organization. The latter is further trained by presentating rhythmic patterns evoking words with different tonic accent, already proposed in synchresis where, however, they were related to simple bisyllabic words. Now rhythm becomes more complex extending to trisyllabic words (slippery, flat and truncated). 
Thoroughly coordinated to the motor area, we go on with the linguistic area including activities that involve vowel sound improvement, so that subjects become aware of their distinctive traits by gradually learning to coordinate the organs used for phonation and articulation as well as for respiratory rhythm.

Absolutely in line with the method basic principle that provides always interconnected activities, stimulation of bed-writing leads [45] to a conscious acquisition of single phonic (phonemes) and graphic (graphemes) units as well as vowels and consonants, which are spatialized from appropriately emphasized easy graphic symbols. A subject learns to know even sound slightest differences, articulation [46] and graphics, starting with discriminating vibrant phonemes which have their own sound from the deaf ones which produce only noise [47]. These acquisitions allow a correct decoding and coding of phono-graphic units and, therefore, a chance to combine them correctly, proceeding slowly to initially reading and writing words at high use frequency and then more and more complex and correct from a graphic-spelling perspective [48].

Analysis marks a real turning point in the cognitive-behavioral area, because a subject who activates the above mentioned selective attention, obtained by coordinating all learnings, gradually manages to organize mental schemes that can start up a mnemonic process, which is obviously a short-term memory [30]. All this has important effects on behaviour, since the awareness of being able to manage a progressively greater number of learning has a significant influence on interests and self-esteem.

\section{Results}

\subsection{Syncresis}

Data highlighted in Table 1 clearly show that subjects' exposure to global stimulations during syncretic phase, sent coordinately and simultaneously to all the aforesaid cerebral areas, according to an inextricable method principle, provides important results in a short time. Starting from the second evaluation already, but even more from the third one, it should be noted that the majority of subjects report positive results in the considered areas related to syncresis. Regarding variables ascribable to cognitive-behavioral area, a supervisory status, which is absent and poor at the beginning, becomes present during following evaluations. It also improves attention capacity in all its aspects: attention level that is mostly low during the first evaluation phase becomes sufficient and good during following evaluations due to carrying out therapeutic interventions; the duration of patients' attention becomes short first, and then it gets prolonged after following stimulations. In line with solicitation simultaneity that characterizes AUGEV method, there are evident improvements in the motor area as well. In particular, an initial detected general dynamic incoordination is completely overcome. Patients who were not able to execute simple orders or who found them difficult to do at first evaluation, are afterwards able to reproduce simple or even complex orders. Subjects show also an improvement in executing simple 
Table 1. Observed variables during syncresis.

\begin{tabular}{|c|c|c|c|c|c|}
\hline Variables & & & Modes & & $\begin{array}{l}\text { Asymptotic } \\
\text { Significance }\end{array}$ \\
\hline Supervisory status & absent & poor & present & & 0.000 \\
\hline Attention: level & poor & sufficient & good & & 0.000 \\
\hline Attention: duration & short & prolonged & & & 0.003 \\
\hline $\begin{array}{l}\text { General dynamic } \\
\text { coordination }\end{array}$ & absent & limited & present & & 0.000 \\
\hline $\begin{array}{l}\text { Understanding and } \\
\text { execution of orders }\end{array}$ & absent & partial & simple & complex & 0.007 \\
\hline $\begin{array}{l}\text { Performing simple } \\
\text { unshielded rhythmic beats }\end{array}$ & absent & wrong & correct & & 0.000 \\
\hline $\begin{array}{c}\text { Word rhythm: performing } \\
\text { a flat bisyllable }\end{array}$ & absent & wrong & occasionally correct & correct & 0.000 \\
\hline $\begin{array}{l}\text { Word rhythm: truncated } \\
\text { bisyllable }\end{array}$ & absent & wrong & occasionally correct & correct & 0.000 \\
\hline Oral praxies & absent & lacking & present & & 0.000 \\
\hline Phono-articulatory praxies & absent & lacking & present & & 0.000 \\
\hline Pronunciation of vowels & absent & altered & slightly altered & correct & 0.000 \\
\hline Execution of graphemes & absent & lacking & good & & 0.000 \\
\hline
\end{tabular}

unshielded rhythmic beats. A similar positive trend in terms of achieved results following the treatments is recorded in executing measures that reproduce the rhythm of flat and truncated bisyllabic words compared to which, at second evaluation already, the share of those who cannot execute them decreases in favor of an increase of those who perform them wrong firstly, then intermittently correct and completely correct. Regarding the linguistic area, incoordination detected in first evaluations involves organization of verbal and written communication, considered unanimously one of the most complex activities of human mind. Thanks to the application of AUGEV method, almost all subjects are gradually able to recover from initial deficits related to oral and phono-articulatory praxis. Progress of vowel pronunciation is also evident: all subjects, who at the time of their taking in charge, were unable to emit vowels, recovered in following evaluations. Grapheme execution completes the picture of variables related to synchresis, towards which almost all subjects show inadequacies, afterwards recovered during following evaluations.

\subsection{First Analysis}

Regarding AUGEV method analytical phase, it is quite clear that in the evaluations following the first one subjects report positive percentages in three variables pertaining to three large perceptive areas: visual, acoustic and proprioceptive. Coordination and simultaneity of stimulations in the above-mentioned areas, which are extremely detailed in the analytical phase, have an important impact in the cognitive-behavioral area: attention becomes selective and begins 
to address pertinent information, a progress that allows a mnemonic process activation, even if it is still a short-term memory. However, the latter becomes a stable acquisition only in second analysis. In the motor area, segmental coordination, which turns out to be absent or limited at the beginning, is acquired by a good number of subjects who become able to perform motor acts based on models that provide personal body awareness. A significant improvement of motor coordination, acoustic perception and short-term memory is obtained by evaluating simple shielded rhythmic beat executions. The start of rhythmic motor skills is also appreciated in executing rhythmic models related to trisyllabic words: in fact, in the fourth evaluation almost all subjects are able to execute word rhythms with three syllables (slippery, flat or truncated). Another important positive element in analytical path progress is data concerning the phonatory setting [49], which are significant of correct establishment of audio-phonator feedbacks. The analytic ability to manage small muscle areas is also evident in the meaning found in variables related to sound pitch within a fifth (remember that 5 are, generally, the shades within which natural speech moves) and in individual vowel sound refinement. In particular, for vowels a, è, i, ò, u [50] considerable improvements are made in evaluations following the first one, with an increasing incidence of subjects able to emit them in a guided manner first, then on a model basis. Some absolutely reliable difficulties remain in correctly producing the two closed vowels "é" and "ó", as they provide for perceptive discrimination and articulatory control not yet achieved by subjects who are acquiring language. The latter is strongly favored by an increasingly conscious use of bed-writing, which allows fixing sound-acoustic patterns by virtue of a coordinated use of graphics and tact-motors. The results in this area, highlighted in Table 2, are also positive: in pronouncing and reading individual alphabetic letters (graphical decoding), in the one concerning a variable combination between consonants and vowels (syllabic decoding), including the more complex consonant-vowel-consonant scheme (pronunciation of caudate syllables and coding of final consonants in syllables), finally in reading true words (lexical decoding) and in writing under phonemic dictation (phoneme-grapheme conversion). Perceptual training on analysis leads a subject to check also minimum differences between very similar phono-graphemes (for example, p-b, f-v, d-t, l-r, c-g): at the fourth evaluation almost all cases are able to decode them correctly. The ability to control graphic stroke improves significantly. Findings show that subjects are progressively acquiring a correct verbo-graphic production.

\subsection{Spectrographic Examination: Definition and Results}

From the qualitative analysis carried out on examined population, it emerges clearly a positive response of all subjects to stimulations contained in Augev method treatment protocol. However, it was considered proper in phono-linguistic field to confirm qualitative data with quantitative evaluations obtained thanks to voice spectrographic analysis. The spectrographic survey represents AUGEV method further strong point, which proceeds innovatively towards 
Table 2. Observed variables during first analysis.

\begin{tabular}{|c|c|c|c|c|c|}
\hline Variables & & & Modes & & $\begin{array}{l}\text { Asymptotic } \\
\text { Significance }\end{array}$ \\
\hline Visual perception & absent & limited & good & excellent & 0.000 \\
\hline Acoustic perception & absent & limited & good & excellent & 0.013 \\
\hline Proprioceptive sensitivity & absent & limited & good & excellent & 0.01 \\
\hline Selective attention & absent & present & & & 0.000 \\
\hline Short-term memory & absent & present & & & 0.136 \\
\hline Segmental coordination & absent & limited & present & & 0.000 \\
\hline Performance of simple rhythmic beatings & absent & wrong & correct & & 0.002 \\
\hline Word rhythm: slippery three-syllable & absent & wrong & occasionally correct & correct & 0.006 \\
\hline Word rhythm: flat three-syllable & absent & wrong & occasionally correct & correct & 0.000 \\
\hline Word rhythm: truncated three-syllable & absent & wrong & occasionally correct & correct & 0.012 \\
\hline Voice setting & undetectable & absent & lacking & present & 0.000 \\
\hline Intonation of sounds within a fifth & absent & altered & present & & 0.000 \\
\hline Vowel pronunciation à & absent & guided & on model: lacking & on model:good & 0.002 \\
\hline Vowel pronunciation è & absent & guided & on model: lacking & on model:good & 0.012 \\
\hline Vowel pronunciation é & absent & guided & on model: lacking & on model:good & 0.118 \\
\hline Vowel pronunciation i & absent & guided & on model: lacking & on model:good & 0.039 \\
\hline Vowel pronunciation ò & absent & guided & on model: lacking & on model:good & 0.04 \\
\hline Vowel pronunciation ó & absent & guided & on model: lacking & on model:good & 0.376 \\
\hline Vowel pronunciation $\mathrm{u}$ & absent & guided & on model: lacking & on model:good & 0.005 \\
\hline Consonant pronunciation & absent & altered & slightly altered & correct & 0.000 \\
\hline Graphematic decoding & altered & partially correct & correct & & 0.04 \\
\hline Syllabic decoding & altered & partially correct & correct & & 0.041 \\
\hline Pronunciation of caudate syllables & absent & altered & correct & & 0.000 \\
\hline Coding of final syllable consonant & altered & partially correct & correct & & 0.000 \\
\hline Lexical decoding & altered & partially correct & correct & & 0.04 \\
\hline Phoneme-grapheme conversion & absent & partial & good & & 0.04 \\
\hline Homographic grapheme decoding & altered & partially correct & correct & & 0.001 \\
\hline Homogeneous grapheme decoding & altered & partially correct & correct & & 0.001 \\
\hline Graphic stroke & uncertain & excessively marked & definite & & 0.006 \\
\hline
\end{tabular}

phono-linguistic evaluation of recording vocal signal data. It is made with a computerized sonograph through which a vocal sample is taken by means of a high sensitivity microphone that records a subject's voice as faithfully as possible. This survey aims at providing objective physical-acoustic and phonetic-acoustic values of voice and language [20]: fundamental frequency, formants, phonatory duration, intensity. In an extremely brief way we report definitions of these parameters: 
- fundamental frequency $\left(\mathrm{F}_{0}\right)$, or first harmonic, is the lowest frequency among those of single waves that form a complex wave. $\mathrm{F}_{0}$ measured in $\mathrm{Hertz}(\mathrm{Hz})$ is perceived as intonation (acute and severe sounds), the linguistic element that identifies utterance melodic trend;

- formants are frequencies resulting from groups of more intense harmonics, for instance multiple frequencies of $\mathrm{F}_{0}$. They are also measured in $\mathrm{Hz}$. The first $\left(\mathrm{F}_{1}\right)$ and the second formants $\left(\mathrm{F}_{2}\right)$ identify individual vowels and are directly implicated in voice resonance mechanism;

- phonatory duration refers to sound emission time, which is exclusively vocalic in our case;

- amplitude is an energy with which a sound wave propagates. Regarding human voice, it is measured in decibel $(\mathrm{dB})$ and is perceived as a sound volume, that is, a quality that distinguishes sounds in weak and strong ones.

We can simply say that sounds generated by a vocal cord vibration (whose frequency is the fundamental one) go into resonance cavities (hypopharynx, oropharynx and rhinopharynx) and here they are amplified by resonance (measurable through the value of formants $\mathrm{F}_{1}$ and $\mathrm{F}_{2}$ ), resulting more intense and acquiring a timbre that characterizes each speaker's voice. Detection and evaluation of vowel signals carried out by a spectrographic examination are indicative of self-monitoring phono-acoustic ability (feed-back) acquired by a subject during an expressive-verbal act. During educational-rehabilitation process each subject performs more spectrographic evaluations, usually coinciding with significant changes that an operator recognizes on a skill/ability level acquired in perception, discrimination and speech sound production. Thanks to these periodic surveys and monitoring spectrographic traces over time, it is possible to target an intervention and verify progressive disappearance of initial anomalies. Referring to the population in our study, it is important to clarify that the majority of subjects could not make this instrumental evaluation from the start, given a total absence of spoken language and, therefore, an inability to emit articulate and finalized sounds. However, it is possible to appreciate in all subjects an acquired ability to emit vocal sounds from the following evaluation already, even if its production still takes place in a guided way in some cases.

These sounds, just sketchy and very inaccurate [51] in the beginning, become more and more defined during evaluation progress and acquire their own individual tone. A confirmation is unequivocally given by comparing the values of $F_{0}, F_{1}, F_{2}$ and $E$, measured for each of seven vowels with the reference physiological ones related to a subject's age and sex. In the table below, for each of the 40 cases, values of fundamental frequency $\left(\mathrm{F}_{0}\right)$, the first $\left(\mathrm{F}_{1}\right)$ and the second formant $\left(F_{2}\right)$ and sound energy $(E)$, recorded in first spectroscopy exam with those detected in the last one, were compared to highlight a sharp tendency to approximate the range that scholars have identified for each vowel as referable to average values falling within the norm.

For the sake of brevity, it was considered appropriate to present only the values measured for vowel "a" (Table 3), considered a typical vocal for its pho- 
no-articulatory characteristics. In reference with fundamental frequency $\left(\mathrm{F}_{0}\right)$, it is possible to see how 29/40 subjects report values falling entirely within reference range in the last evaluation, while 7 of the remaining 11 show how they have started to fall within standard values.

Data related to first $\left(\mathrm{F}_{1}\right)$ and to second formant $\left(\mathrm{F}_{2}\right)$ are also positive, since respectively $65 \%$ and $67.5 \%$ of the cases show an improvement of last spectrographic examination compared to the first one with values that get close to the average values measured for vowel "a" (Tables 4-6). These are very interesting

Table 3. Basic frequency $\left(\mathrm{F}_{0}\right)$. Case distribution by fundamental vocal frequency $\left(\mathrm{F}_{0}\right)$ a.

\begin{tabular}{|c|c|c|c|c|c|c|c|c|c|c|c|}
\hline Cases & Sex & Age & $\begin{array}{l}\text { First spectrographic } \\
\text { examination }\end{array}$ & $\begin{array}{l}\text { Reference } \\
\text { range }\end{array}$ & $\begin{array}{c}\text { Average value } \\
\text { reference }\end{array}$ & $\begin{array}{l}\text { Execution } \\
1^{\circ} \text { exam }\end{array}$ & Age & $\begin{array}{c}\text { Last } \\
\text { spectrographic }\end{array}$ & $\begin{array}{l}\text { Reference } \\
\text { range }\end{array}$ & $\begin{array}{l}\text { Average value } \\
\text { reference }\end{array}$ & $\begin{array}{l}\text { Execution } \\
\text { last exam }\end{array}$ \\
\hline 1 & $\mathrm{M}$ & 6 & 245 & $280-365$ & 325 & guided & 12 & 234.57 & $170-245$ & 210 & on model \\
\hline 2 & $\mathrm{~F}$ & 4 & 324 & $310-450$ & 355 & on model & 14 & 245 & $195-270$ & 235 & on model \\
\hline 3 & M & 8 & 172.27 & $260-330$ & 295 & guided & 10 & 256.4 & $195-275$ & 235 & on model \\
\hline 4 & M & 13 & 245 & $155-230$ & 195 & on model & 18 & 149.52 & $100-155$ & 125 & on model \\
\hline 5 & $\mathrm{M}$ & 6 & 153.13 & $280-365$ & 325 & guided & 8 & 280.12 & $260-330$ & 295 & on model \\
\hline 6 & M & 7 & 268.9 & $260-330$ & 295 & on model & 9 & 272.12 & $220-300$ & 260 & on model \\
\hline 7 & M & 8 & 402 & $260-330$ & 295 & guided & 22 & 115.23 & $100-155$ & 125 & on model \\
\hline 8 & $\mathrm{~F}$ & 8 & 190.09 & $245-310$ & 280 & on model & 10 & 166.72 & $225-320$ & 265 & on model \\
\hline 9 & M & 8 & 268.9 & $260-330$ & 295 & on model & 11 & 254.54 & $185-260$ & 225 & on model \\
\hline 10 & M & 5 & 290.13 & $300-390$ & 350 & on model & 13 & 191.69 & $155-230$ & 195 & on model \\
\hline 11 & M & 9 & 239.67 & $220-300$ & 260 & on model & 10 & 266.43 & $195-275$ & 235 & on model \\
\hline 12 & M & 5 & 200.45 & $300-390$ & 350 & on model & 8 & 263.53 & $260-330$ & 295 & on model \\
\hline 13 & M & 6 & 204.17 & $280-365$ & 325 & on model & 8 & 197 & $260-330$ & 295 & on model \\
\hline 14 & M & 5 & 180.69 & $300-390$ & 350 & on model & 6 & 167.46 & $280-365$ & 325 & on model \\
\hline 15 & M & 6 & 212.02 & $280-365$ & 325 & guided & 12 & 218.7 & $170-245$ & 210 & on model \\
\hline 16 & M & 9 & 193.42 & $220-300$ & 260 & guided & 12 & 177.37 & $170-245$ & 210 & on model \\
\hline 17 & M & 8 & 204.17 & $260-330$ & 295 & on model & 11 & 218.84 & $185-260$ & 225 & on model \\
\hline 18 & $\mathrm{M}$ & 10 & 147 & $195-275$ & 235 & on model & 12 & 221.33 & $170-245$ & 225 & on model \\
\hline 19 & M & 4 & 172.27 & $320-425$ & 375 & on model & 15 & 160.34 & $130-195$ & 155 & on model \\
\hline 20 & M & 5 & 234.57 & $300-390$ & 350 & on model & 9 & 163.45 & $220-300$ & 260 & on model \\
\hline 21 & M & 5 & 159.78 & $300-390$ & 350 & on model & 12 & 134.5 & $170-245$ & 210 & on model \\
\hline 22 & M & 2 & 230.02 & $370-525$ & 445 & guided & 4 & 286.39 & $320-425$ & 375 & guided \\
\hline 23 & $\mathrm{M}$ & 12 & 225 & $170-245$ & 210 & on model & 13 & 139.81 & $155-230$ & 195 & on model \\
\hline 24 & $\mathrm{M}$ & 5 & 225 & $300-390$ & 350 & on model & 12 & 193.42 & $170-245$ & 210 & on model \\
\hline 25 & M & 8 & 162.13 & $260-330$ & 295 & on model & 10 & 247.96 & $195-275$ & 235 & on model \\
\hline 26 & $\mathrm{~F}$ & 5 & 250.57 & $290-425$ & 335 & on model & 7 & 261.94 & $245-350$ & 290 & on model \\
\hline 27 & M & 18 & 120.81 & $100-155$ & 125 & on model & 19 & 137.05 & $100-155$ & 125 & on model \\
\hline 28 & M & 4 & 181.93 & $320-425$ & 375 & on model & 6 & 250.22 & $280-365$ & 325 & on model \\
\hline
\end{tabular}




\section{Continued}

\begin{tabular}{|c|c|c|c|c|c|c|c|c|c|c|c|}
\hline 29 & $\mathrm{~F}$ & 7 & 225.19 & $245-350$ & 290 & on model & 9 & 165.52 & $235-335$ & 275 & on model \\
\hline 30 & $\mathrm{M}$ & 3 & 200.45 & $340-460$ & 400 & on model & 9 & 265.8 & $220-300$ & 260 & on model \\
\hline 32 & $\mathrm{M}$ & 10 & 250.57 & $195-275$ & 235 & on model & 18 & 207.43 & $100-155$ & 125 & on model \\
\hline 33 & $\mathrm{~F}$ & 7 & 190.09 & $245-350$ & 290 & on model & 15 & 236.18 & $185-260$ & 220 & on model \\
\hline 34 & $\mathrm{M}$ & 3 & 282.69 & $340-460$ & 400 & on model & 10 & 275.63 & $195-275$ & 235 & on model \\
\hline 35 & $\mathrm{M}$ & 8 & 268.9 & $260-330$ & 295 & on model & 10 & 249.91 & $195-275$ & 235 & on model \\
\hline 36 & M & 10 & 277.9 & $195-275$ & 235 & guided & 11 & 245.63 & $185-260$ & 225 & on model \\
\hline 37 & M & 3 & 168.25 & $340-460$ & 400 & on model & 4 & 185.24 & $320-425$ & 375 & on model \\
\hline 39 & $\mathrm{M}$ & 4 & 175.3 & $320-425$ & 375 & on model & 5 & 150.53 & $300-390$ & 350 & on model \\
\hline 40 & M & 5 & 275.63 & $300-390$ & 350 & on model & 10 & 235.7 & $195-275$ & 235 & on model \\
\hline
\end{tabular}

Table 4. Case distribution by first formant $\left(\mathrm{F}_{1}\right)$ vowel a.

\begin{tabular}{|c|c|c|c|c|c|c|c|c|c|}
\hline Cases & Sex & $\begin{array}{l}\text { Age } \\
1^{\circ}\end{array}$ & $\begin{array}{c}\text { First } \\
\text { spectrographic } \\
\text { examination }\end{array}$ & $\begin{array}{l}\text { Reference } \\
\text { range }\end{array}$ & $\begin{array}{c}\text { Execution } \\
1^{\circ} \text { exam }\end{array}$ & $\begin{array}{c}\text { Age last } \\
\text { one }\end{array}$ & $\begin{array}{l}\text { Last } \\
\text { spectrographic } \\
\text { examination }\end{array}$ & $\begin{array}{c}\text { Reference } \\
\text { range }\end{array}$ & $\begin{array}{l}\text { Execution } \\
\text { last one }\end{array}$ \\
\hline 1 & M & 6 & 976.6 & 700 & guided & 12 & 696.4 & 700 & guided \\
\hline 2 & $\mathrm{~F}$ & 4 & 623.3 & 700 & on model & 14 & 938.8 & 700 & on model \\
\hline 3 & M & 10 & 1003 & 700 & guided & 10 & 675.8 & 700 & on model \\
\hline 4 & M & 13 & 1067 & 700 & on model & 18 & 775.5 & 700 & on model \\
\hline 5 & M & 6 & 995.9 & 700 & guided & 8 & 1037 & 700 & on model \\
\hline 6 & M & 7 & 1071 & 700 & on model & 9 & 840.7 & 700 & on model \\
\hline 7 & M & 8 & 784 & 700 & guided & 22 & 639 & 700 & on model \\
\hline 8 & F & 8 & 1105 & 700 & on model & 10 & 989.6 & 700 & on model \\
\hline 9 & M & 8 & 1027 & 700 & on model & 11 & 911.1 & 700 & on model \\
\hline 10 & M & 5 & 1463 & 700 & on model & 13 & 870.6 & 700 & on model \\
\hline 11 & M & 9 & 982.9 & 700 & on model & 10 & 913.6 & 700 & on model \\
\hline 12 & M & 5 & 882.7 & 700 & on model & 8 & 1019 & 700 & on model \\
\hline 13 & M & 6 & 944 & 700 & on model & 8 & 802.2 & 700 & on model \\
\hline 14 & M & 5 & 632.7 & 700 & on model & 6 & 741.5 & 700 & on model \\
\hline 15 & M & 6 & 867.6 & 700 & on model & 12 & 845.9 & 700 & on model \\
\hline 16 & M & 9 & 951 & 700 & on model & 12 & 723.2 & 700 & on model \\
\hline 17 & M & 8 & 986.3 & 700 & on model & 11 & 860.7 & 700 & on model \\
\hline 18 & M & 10 & 773.4 & 700 & on model & 12 & 917.2 & 700 & on model \\
\hline 19 & M & 4 & 1030 & 700 & on model & 15 & 1372 & 700 & on model \\
\hline 20 & M & 5 & 1297 & 700 & on model & 9 & 993.5 & 700 & on model \\
\hline 21 & M & 5 & 1060 & 700 & on model & 12 & 1132 & 700 & on model \\
\hline
\end{tabular}


A. Campanella et al.

\section{Continued}

\begin{tabular}{lccccccccc}
\hline 22 & M & 2 & 824.1 & 700 & guided & 4 & 1157 & 700 & guided \\
23 & M & 12 & 680.6 & 700 & on model & 13 & 715.8 & 700 & on model \\
24 & M & 5 & 1039 & 700 & on model & 12 & 712.9 & 700 & on model \\
25 & M & 8 & 820.2 & 700 & on model & 10 & 555.6 & 700 & on model \\
26 & F & 5 & 1029 & 700 & on model & 7 & 963.2 & 700 & on model \\
27 & M & 18 & 921.3 & 700 & on model & 19 & 849.1 & 700 & on model \\
28 & M & 4 & 1045 & 700 & on model & 6 & 1036.74 & 700 & on model \\
29 & F & 7 & 1447 & 700 & on model & 9 & 1276 & 700 & on model \\
30 & M & 3 & 1230 & 700 & on model & 9 & 1080 & 700 & on model \\
31 & M & 8 & 750.8 & 700 & on model & 9 & 1306 & 700 & on model \\
32 & M & 10 & 1054 & 700 & on model & 18 & 1130 & 700 & on model \\
33 & F & 7 & 894.5 & 700 & on model & 15 & 1010 & 700 & on model \\
34 & M & 3 & 1093 & 700 & on model & 10 & 1001 & 700 & on model \\
35 & M & 8 & 1055 & 700 & on model & 10 & 998.4 & 700 & on model \\
36 & M & 10 & 352.1 & 700 & guided & 11 & 297.7 & 700 & on model \\
37 & M & 3 & 649.3 & 700 & on model & 4 & 1136 & 700 & on model \\
38 & F & 5 & 1364 & 700 & on model & 10 & 848.1 & 700 & on model \\
39 & M & 4 & 913.7 & 700 & on model & 5 & 1214 & 700 & on model \\
40 & M & 5 & 944.4 & 700 & on model & 10 & 1045 & 700 & on model \\
\hline
\end{tabular}

Table 5. Case distribution as to second formant $\left(\mathrm{F}_{2}\right)$ vowel a.

\begin{tabular}{|c|c|c|c|c|c|c|c|c|c|}
\hline Cases & Sex & Age & $\begin{array}{c}\text { First } \\
\text { spectrographic } \\
\text { examination }\end{array}$ & $\begin{array}{c}\text { Reference } \\
\text { range }\end{array}$ & $\begin{array}{c}\text { Execution } \\
1^{\circ} \text { exam }\end{array}$ & Age & $\begin{array}{c}\text { Last } \\
\text { spectrographic } \\
\text { examination }\end{array}$ & $\begin{array}{c}\text { Reference } \\
\text { range }\end{array}$ & $\begin{array}{c}\text { Execution } \\
\text { last one }\end{array}$ \\
\hline 1 & M & 6 & 1803 & 1250 & guided & 12 & 1424 & 1250 & on model \\
\hline 2 & $\mathrm{~F}$ & 4 & 1470 & 1250 & on model & 14 & 1670 & 1250 & on model \\
\hline 3 & M & 8 & 1390 & 1250 & guided & 10 & 1367 & 1250 & on model \\
\hline 4 & M & 13 & 1462 & 1250 & on model & 18 & 1433 & 1250 & on model \\
\hline 5 & M & 6 & 1391 & 1250 & guided & 8 & 1707 & 1250 & on model \\
\hline 6 & M & 7 & 1619 & 1250 & on model & 9 & 1163 & 1250 & on model \\
\hline 7 & M & 8 & 1187 & 1250 & guided & 22 & 1682 & 1250 & on model \\
\hline 8 & $\mathrm{~F}$ & 8 & 1979 & 1250 & on model & 10 & 1919 & 1250 & on model \\
\hline 9 & M & 8 & 1735 & 1250 & on model & 11 & 1266 & 1250 & on model \\
\hline 10 & M & 5 & 2582 & 1250 & on model & 13 & 1319 & 1250 & on model \\
\hline 11 & M & 9 & 1436 & 1250 & on model & 10 & 1219 & 1250 & on model \\
\hline 12 & M & 5 & 1794 & 1250 & on model & 8 & 1735 & 1250 & on model \\
\hline 13 & M & 6 & 1895 & 1250 & on model & 8 & 1253 & 1250 & on model \\
\hline 14 & M & 5 & 1507 & 1250 & on model & 6 & 1549 & 1250 & on model \\
\hline
\end{tabular}




\section{Continued}

\begin{tabular}{|c|c|c|c|c|c|c|c|c|c|}
\hline 15 & M & 6 & 2325 & 1250 & on model & 12 & 1566 & 1250 & on model \\
\hline 16 & M & 9 & 1603 & 1250 & guided & 12 & 1908 & 1250 & on model \\
\hline 17 & M & 8 & 1556 & 1250 & on model & 11 & 1828 & 1250 & on model \\
\hline 18 & M & 10 & 1851 & 1250 & on model & 12 & 1981 & 1250 & on model \\
\hline 19 & M & 4 & 2685 & 1250 & on model & 15 & 2919 & 1250 & on model \\
\hline 20 & M & 5 & 2161 & 1250 & on model & 9 & 1387 & 1250 & on model \\
\hline 21 & M & 5 & 1864 & 1250 & on model & 12 & 1556 & 1250 & on model \\
\hline 22 & M & 2 & 1859 & 1250 & guided & 4 & 1949 & 1250 & guided \\
\hline 23 & M & 12 & 1693 & 1250 & on model & 13 & 1456 & 1250 & on model \\
\hline 24 & M & 5 & 1745 & 1250 & on model & 12 & 1357 & 1250 & on model \\
\hline 25 & M & 8 & 1740 & 1250 & on model & 10 & 1586 & 1250 & on model \\
\hline 26 & $\mathrm{~F}$ & 5 & 1677 & 1250 & on model & 7 & 1864 & 1250 & on model \\
\hline 27 & M & 18 & 1633 & 1250 & on model & 19 & 1600 & 1250 & on model \\
\hline 28 & M & 4 & 2047 & 1250 & on model & 6 & 1795 & 1250 & on model \\
\hline 29 & $\mathrm{~F}$ & 7 & 1889 & 1250 & on model & 9 & 1664 & 1250 & on model \\
\hline 30 & M & 3 & 2007 & 1250 & on model & 9 & 1799 & 1250 & on model \\
\hline 31 & M & 8 & 1694 & 1250 & on model & 9 & 1953 & 1250 & on model \\
\hline 32 & M & 10 & 1680 & 1250 & on model & 18 & 2949 & 1250 & on model \\
\hline 33 & $\mathrm{~F}$ & 7 & 1935 & 1250 & on model & 15 & 1756 & 1250 & on model \\
\hline 34 & M & 3 & 1960 & 1250 & on model & 10 & 1393 & 1250 & on model \\
\hline 35 & M & 8 & 1578 & 1250 & on model & 10 & 1493 & 1250 & on model \\
\hline 36 & M & 10 & 1388 & 1250 & guided & 11 & 1295 & 1250 & on model \\
\hline 37 & M & 3 & 1512 & 1250 & on model & 4 & 1823 & 1250 & on model \\
\hline 38 & $\mathrm{~F}$ & 5 & 1835 & 1250 & on model & 10 & 1832 & 1250 & on model \\
\hline 39 & M & 4 & 1770 & 1250 & on model & 5 & 1924 & 1250 & on model \\
\hline 40 & M & 5 & 1992 & 1250 & on model & 10 & 1491 & 1250 & on model \\
\hline
\end{tabular}

Table 6. Case distribution by amplitude (E) Vowel a.

\begin{tabular}{|c|c|c|c|c|c|c|c|c|c|}
\hline Cases & Sex & Age & $\begin{array}{c}\text { First } \\
\text { spectrographic } \\
\text { examination }\end{array}$ & $\begin{array}{c}\text { Reference } \\
\text { range }\end{array}$ & $\begin{array}{c}\text { Execution } \\
1^{\circ} \text { exam }\end{array}$ & Age & $\begin{array}{c}\text { Last } \\
\text { spectrographic } \\
\text { examination }\end{array}$ & $\begin{array}{c}\text { Reference } \\
\text { range }\end{array}$ & $\begin{array}{l}\text { Execution } \\
\text { last one }\end{array}$ \\
\hline 1 & M & 6 & 53.79 & $50-65$ & guided & 12 & 64.53 & $50-65$ & on model \\
\hline 2 & $\mathrm{~F}$ & 4 & 60.28 & $50-65$ & on model & 14 & 62.85 & $50-65$ & on model \\
\hline 3 & M & 8 & 61.79 & $50-65$ & guided & 10 & 61.32 & $50-65$ & on model \\
\hline 4 & M & 13 & 62.84 & $50-65$ & on model & 18 & 58.27 & $50-65$ & on model \\
\hline 5 & M & 6 & 56.84 & $50-65$ & guided & 8 & 68 & $50-65$ & on model \\
\hline 6 & M & 7 & 59.8 & $50-65$ & on model & 9 & 67.92 & $50-65$ & on model \\
\hline 7 & M & 8 & 50 & $50-65$ & guided & 22 & 65.84 & $50-65$ & on model \\
\hline
\end{tabular}




\section{Continued}

\begin{tabular}{|c|c|c|c|c|c|c|c|c|c|}
\hline 8 & $\mathrm{~F}$ & 8 & 63.74 & $50-65$ & on model & 10 & 65.81 & $50-65$ & on mode \\
\hline 9 & $\mathrm{M}$ & 8 & 59.28 & $50-65$ & on model & 11 & 59.12 & $50-65$ & on mode \\
\hline 10 & $\mathrm{M}$ & 5 & 60.61 & $50-65$ & on model & 13 & 65.69 & $50-65$ & on mode \\
\hline 11 & $\mathrm{M}$ & 9 & 56.41 & $50-65$ & on model & 10 & 61.36 & $50-65$ & on mode \\
\hline 12 & $\mathrm{M}$ & 5 & 58.59 & $50-65$ & on model & 8 & 59.66 & $50-65$ & on mode \\
\hline 13 & $\mathrm{M}$ & 6 & 74.54 & $50-65$ & on model & 8 & 59.33 & $50-65$ & on mode \\
\hline 14 & M & 5 & 61.39 & $50-65$ & on model & 6 & 56 & $50-65$ & on mode \\
\hline 15 & M & 6 & 66.05 & $50-65$ & on model & 12 & 62.16 & $50-65$ & on mode \\
\hline 16 & $\mathrm{M}$ & 9 & 72.95 & $50-65$ & guided & 12 & 65.47 & $50-65$ & on mode \\
\hline 17 & $\mathrm{M}$ & 8 & 58.15 & $50-65$ & on model & 11 & 57.34 & $50-65$ & on mode \\
\hline 18 & M & 10 & 62.27 & $50-65$ & on model & 12 & 57.85 & $50-65$ & on mode \\
\hline 19 & M & 4 & 67.2 & $50-65$ & on model & 15 & 64.67 & $50-65$ & on mode \\
\hline 20 & M & 5 & 67.89 & $50-65$ & on model & 9 & 62.37 & $50-65$ & on mode \\
\hline 21 & $\mathrm{M}$ & 5 & 69.04 & $50-65$ & on model & 12 & 63.26 & $50-65$ & on mode \\
\hline 22 & $\mathrm{M}$ & 2 & 61.98 & $50-65$ & guided & 4 & 69.3 & $50-65$ & guided \\
\hline 23 & $\mathrm{M}$ & 12 & 56.34 & $50-65$ & on model & 13 & 61.4 & $50-65$ & on mode \\
\hline 24 & $\mathrm{M}$ & 5 & 62.98 & $50-65$ & on model & 12 & 61.5 & $50-65$ & on mode \\
\hline 25 & $\mathrm{M}$ & 8 & 64.39 & $50-65$ & on model & 10 & 57.81 & $50-65$ & on mode \\
\hline 26 & $\mathrm{~F}$ & 5 & 60.47 & $50-65$ & on model & 7 & 58.35 & $50-65$ & on mode \\
\hline 27 & M & 18 & 70.77 & $50-65$ & on model & 19 & 62.7 & $50-65$ & on mode \\
\hline 28 & $\mathrm{M}$ & 4 & 65.49 & $50-65$ & on model & 6 & 55.06 & $50-65$ & on mode \\
\hline 29 & $\mathrm{~F}$ & 7 & 80.67 & $50-65$ & on model & 9 & 63.14 & $50-65$ & on mode \\
\hline 30 & $\mathrm{M}$ & 3 & 70.98 & $50-65$ & on model & 9 & 64.81 & $50-65$ & on mode \\
\hline 31 & $\mathrm{M}$ & 8 & 62.85 & $50-65$ & on model & 9 & 63.09 & $50-65$ & on mode \\
\hline 32 & $\mathrm{M}$ & 10 & 66.77 & $50-65$ & on model & 18 & 58.48 & $50-65$ & on mode \\
\hline 33 & $\mathrm{~F}$ & 7 & 71.62 & $50-65$ & on model & 15 & 64.51 & $50-65$ & on mode \\
\hline 34 & $\mathrm{M}$ & 3 & 66.73 & $50-65$ & on model & 10 & 66.41 & $50-65$ & on mode \\
\hline 35 & $\mathrm{M}$ & 8 & 61.97 & $50-65$ & on model & 10 & 66.46 & $50-65$ & on mode \\
\hline 36 & $\mathrm{M}$ & 10 & 68.99 & $50-65$ & guided & 11 & 53.41 & $50-65$ & on mode \\
\hline 37 & M & 3 & 58.49 & $50-65$ & on model & 4 & 63.82 & $50-65$ & on mode \\
\hline 38 & $\mathrm{~F}$ & 5 & 67.25 & $50-65$ & on model & 10 & 54.5 & $50-65$ & on mode \\
\hline 39 & $\mathrm{M}$ & 4 & 73.12 & $50-65$ & on model & 5 & 64.57 & $50-65$ & on mode \\
\hline 40 & M & 5 & 55.35 & $50-65$ & on model & 10 & 60.64 & $50-65$ & on mode \\
\hline
\end{tabular}

data, if we consider that $22 / 40$ of the subjects do not have a starting spectrographic evaluation, because they were initially completely unable to emit vocal sounds as already mentioned, whereas 4 of the remaining 18 were able to emit vowel sounds in the initial examination by guided mode only, that is, by phoneme phono-articulatory setting. Referring to what briefly explained in synthetic 
introductory notes about formants and remembering how the height of the first two $F_{1}$ and $F_{2}$ determines differences among vowels, we can well understand that values of the latter go to approximate reference value as a subject becomes more coordinated in articulating vowel sounds, a skill that acquires completely by completing the analytic phase (at the end of second analysis).

Regarding Energy, almost the totality of study population, that is $36 / 40$ subjects, reports values within reference range, demonstrating a progressive acquisition of coordination and therefore self-control on vowel sound emission.

In order to prove more clearly what has been claimed so far regarding the positive evolution of educational-rehabilitation path implemented by AUGEV method, spectrographic exams of 6 subjects belonging to the population of this study are shown below. An employed method regards a presentation, for each of the 6 cases, of first and last performed examination and a selection of vowel "a" as "typical vowel". It is clear that initial examinations show marked anomalies in path time progressing (represented on the abscissa axis): an harmonic texture is generally not structured yet (Figure 4(a), Figure 5(a), Figure 7(a)) or irregular (Figure 4(a), Figure 5(a), Figure 7(a)), which is an index of a bad oropharyngeal resonance and, therefore, a missed or incorrect activation of phono-acoustic feedbacks when going back to causes. Obviously, also time trend of frequencies $\left(F_{0}, F_{1}, F_{2}\right)$ and amplitude $(E)$ is initially strongly irregular. Values measured by an instrument along with vocal segment to be analyzed are indicated by colored dots, where each color identifies a different parameter: blue color is combined with $F_{0}$, red and orange respectively with $F_{1}$ and $F_{2}$ and brown color with $E$. In no-pathological conditions, points of the same color are arranged next to each other in an ordered frequency alignment. In the examples shown, it is easy instead to see how the first tests show a markedly anomalous pattern with migrations (Figures 2(a)-7(a)), rarefactions (Figure 5(a), Figure 6(a)) and/or frequent

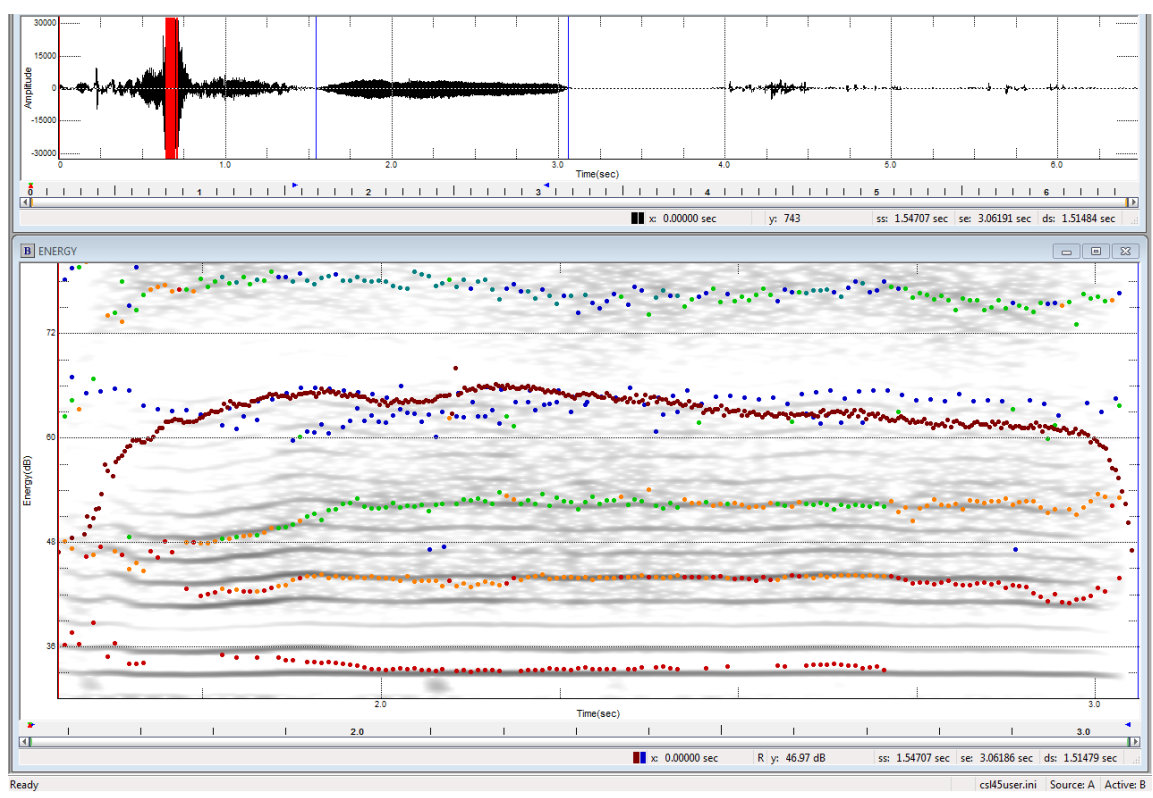

(a) 


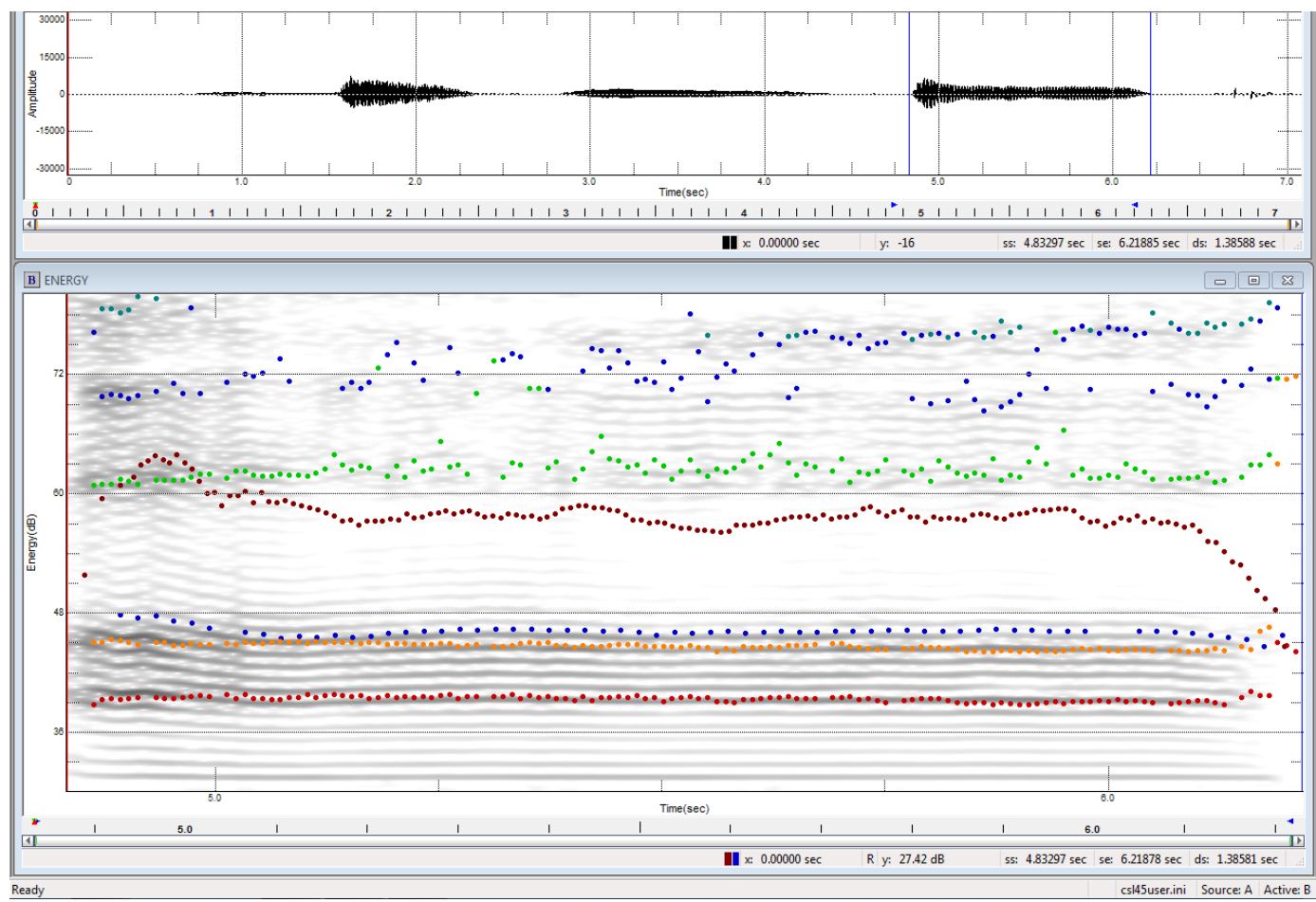

(b)

Figure 2. (a) Spectral examination of the vocal signal. Legend of all the figures beneath. Symbology of the phonetic-acoustic parameters detected in the spectrographic examination: $\bullet \bullet \bullet \bullet \bullet \bullet \bullet \bullet \bullet=$ Fundamental Frequency (Fo), measured in Hz; $\bullet \bullet \bullet \bullet \bullet \bullet \bullet \bullet=$ First Formant $\left(\mathrm{F}_{1}\right)$, measured in Hz; $\bullet \bullet \bullet \bullet \bullet \bullet \bullet \bullet=$ Second Formantt $\left(\mathrm{F}_{2}\right)$, misurata in $\mathrm{Hz}$; $\bullet \bullet \bullet \bullet \bullet \bullet=$ Energy $(\mathrm{E})$, misurata in $\mathrm{dB}$; (b) Spectral examination of the vocal signal.

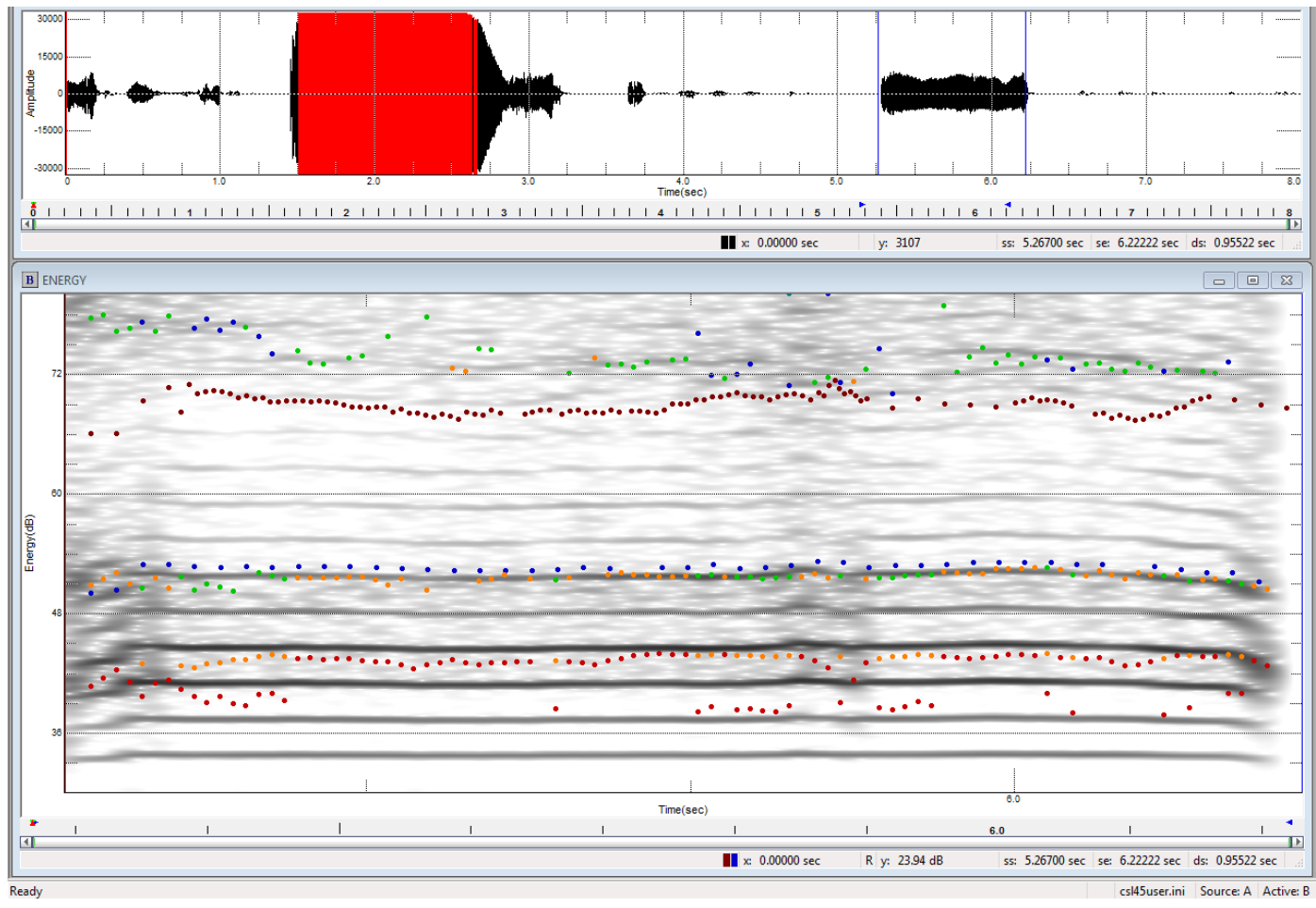

(a) 


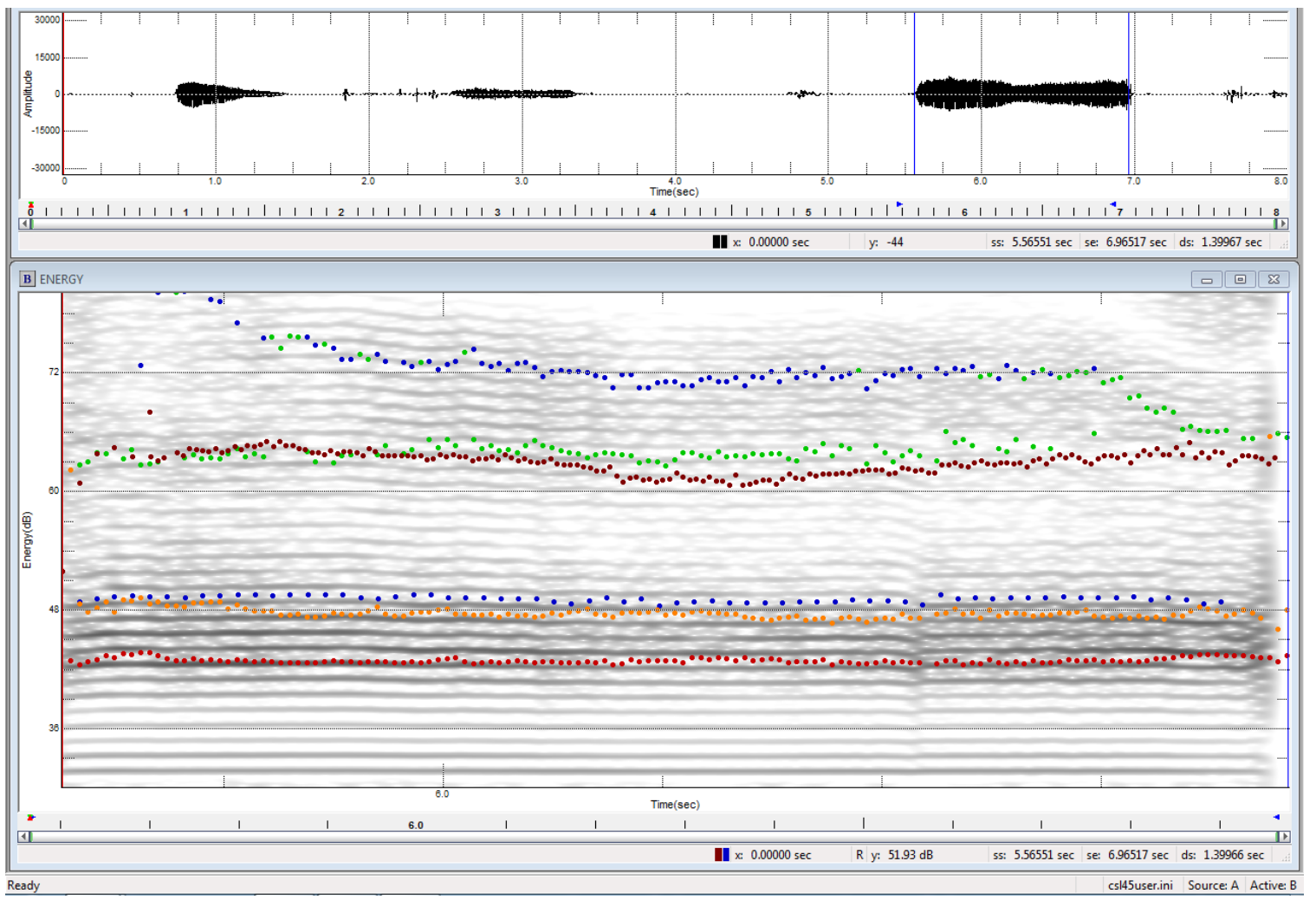

(b)

Figure 3. (a) Spectral examination of the vocal signal; (b) Spectral examination of the vocal signal.

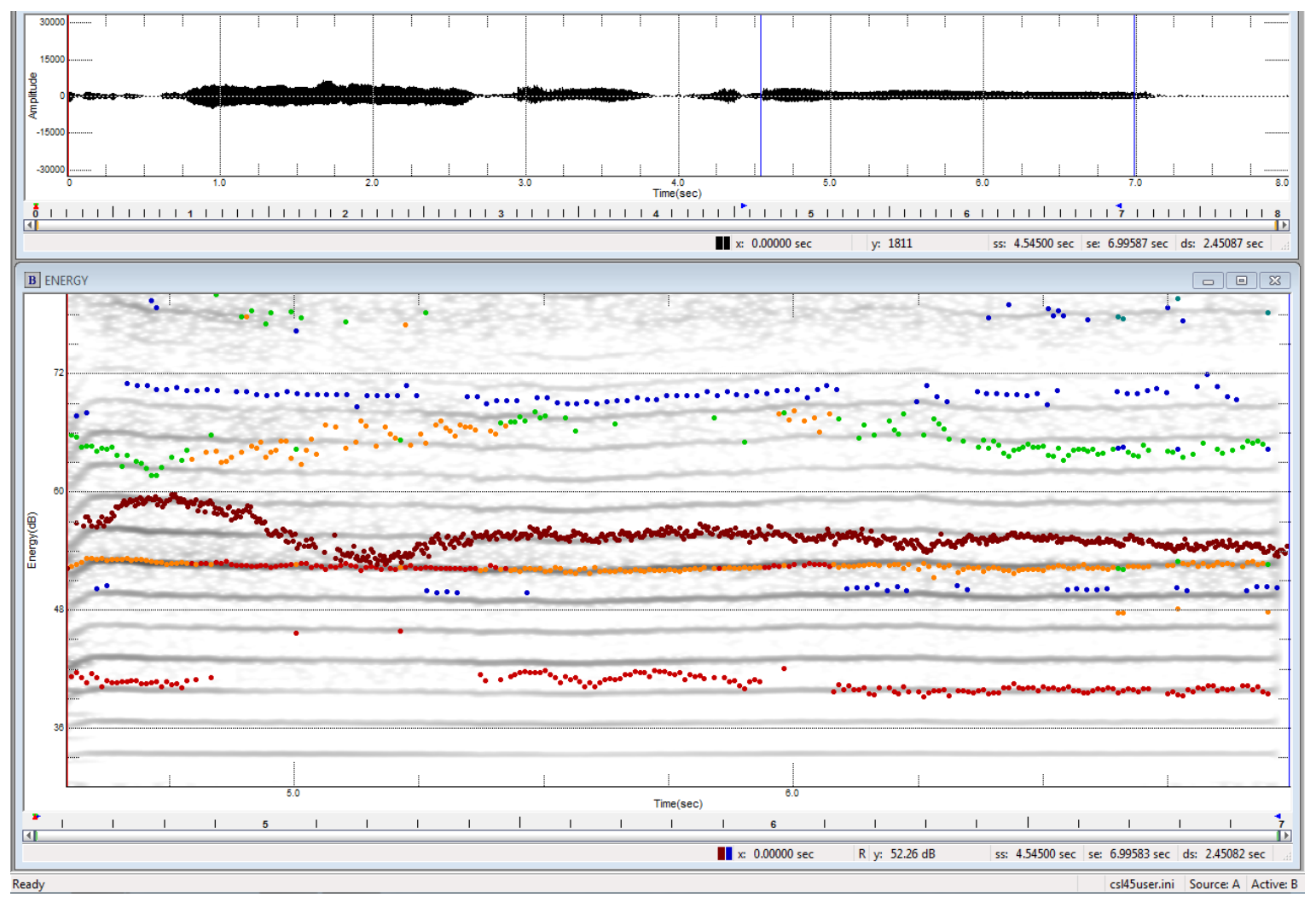

(a) 


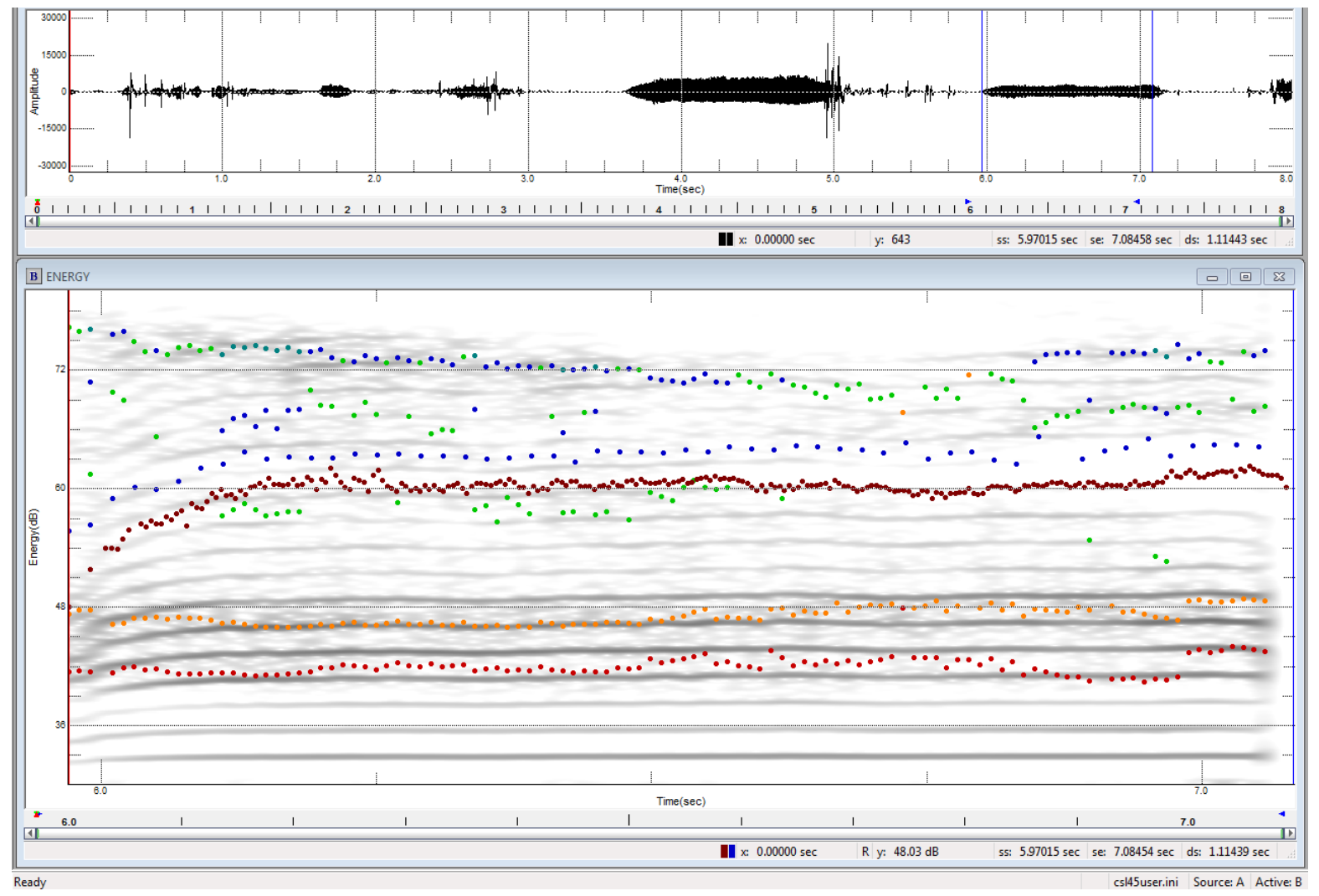

(b)

Figure 4. (a) Spectral examination of the vocal signal; (b) Spectral examination of the vocal signal.

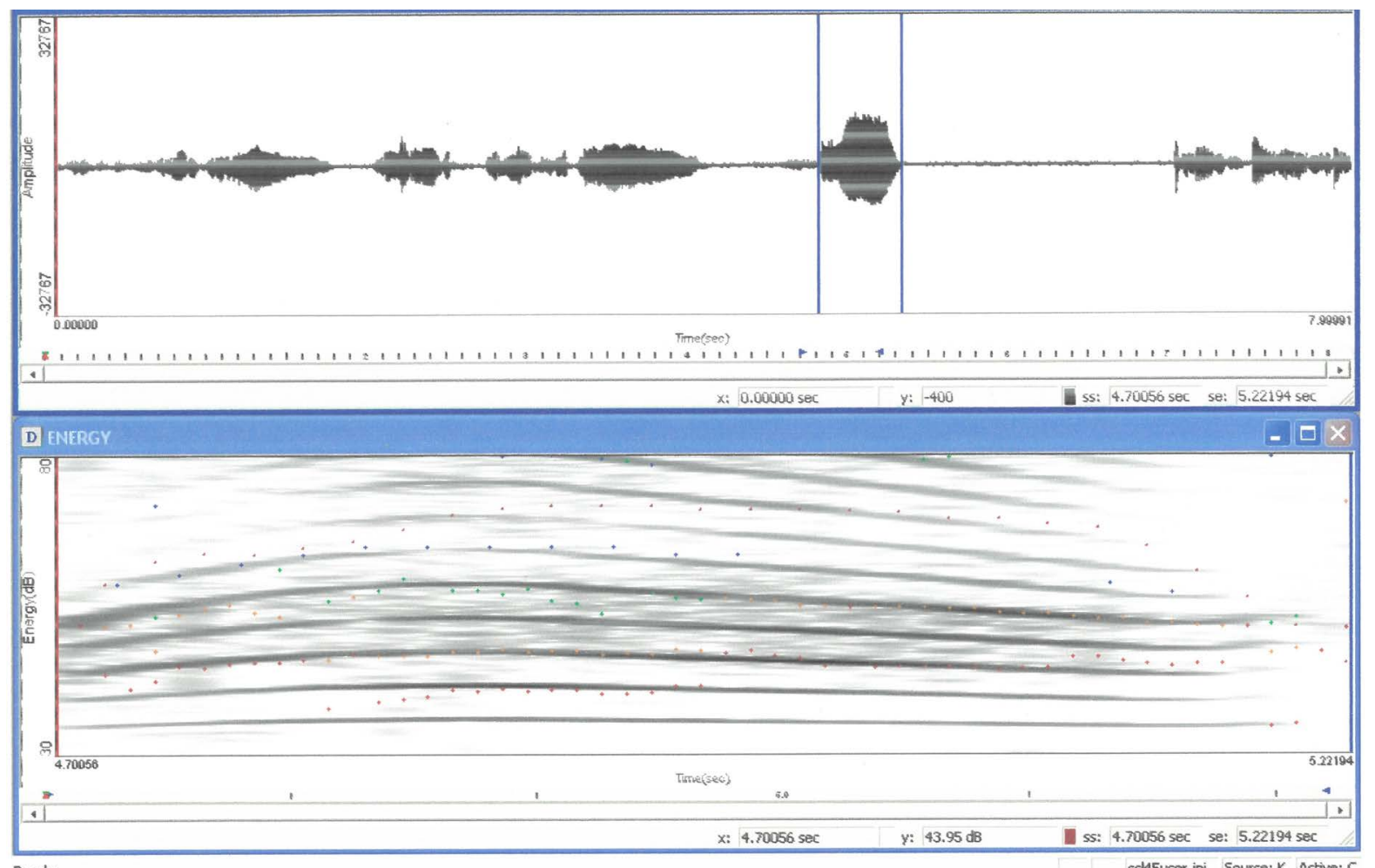

(a) 


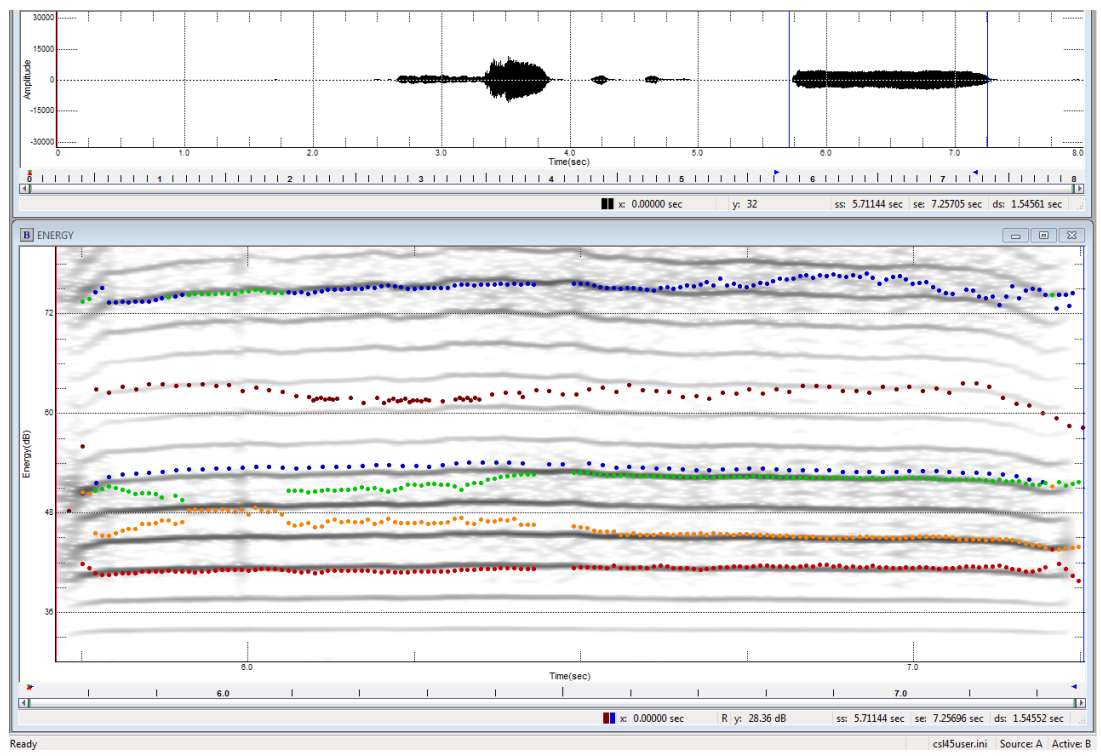

(b)

Figure 5. (a) Spectral examination of the vocal signal; (b) Spectral examination of the vocal signal.

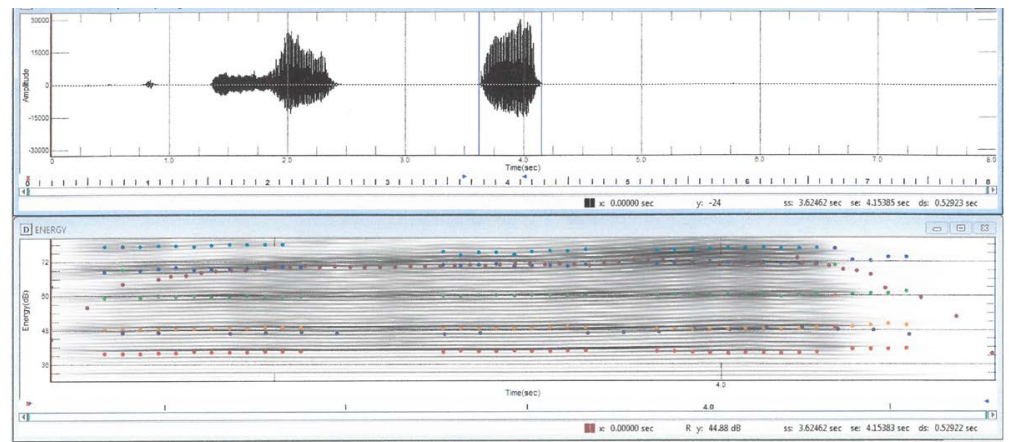

(a)

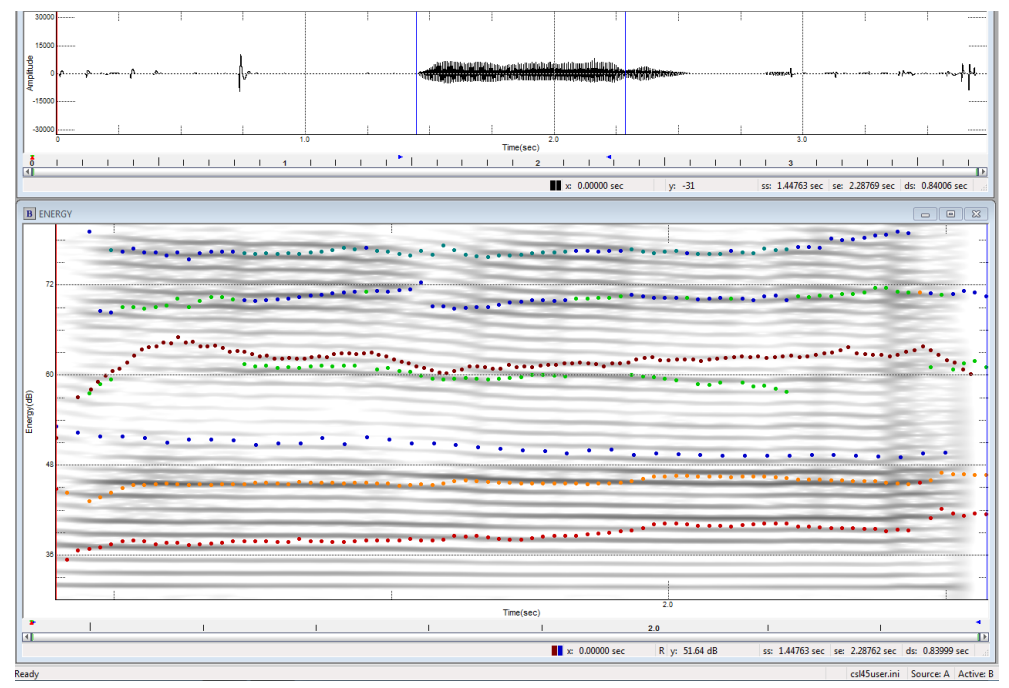

(b)

Figure 6. (a) Spectral examination of the vocal signal. (b) Spectral examination of the vocal signal. 


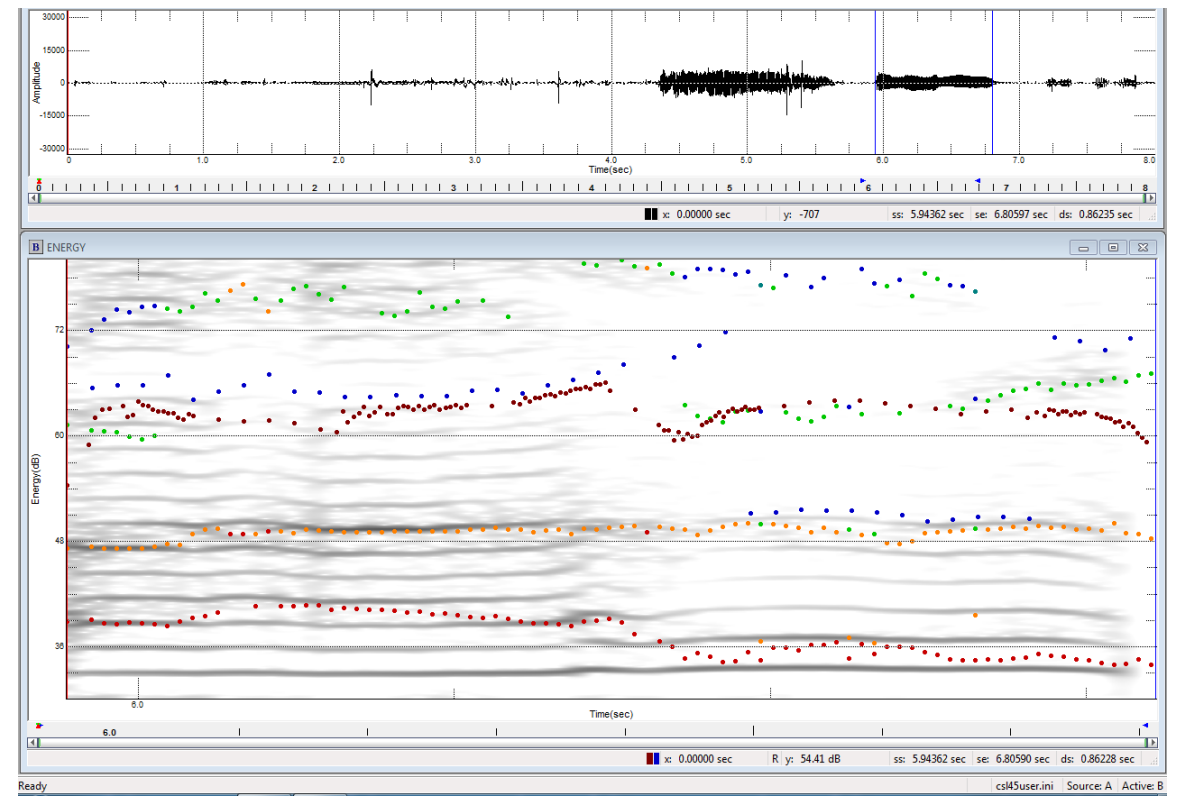

(a)

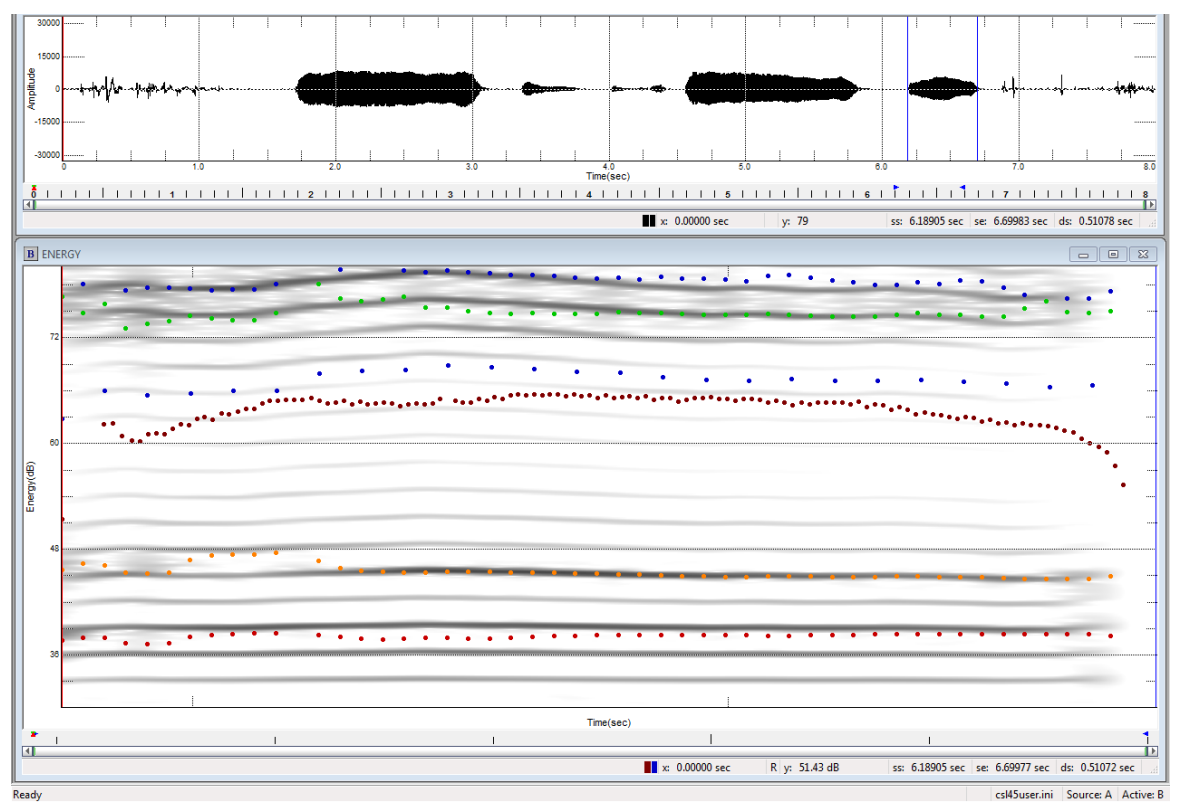

(b)

Figure 7. (a) Spectral examination of the vocal signal; (b) Spectral examination of the vocal signal.

intrusions in an harmonic texture (Figure 2(a), Figures 4(a)-7(a)). In a spectrographic framework, an aperiodic signal (noise) is often present (Figures 2(a)-6(a)), sometimes very strongly, which at high frequencies is to be mostly related to insufficient tension and cordial adduction, with a consequent fugatory air leak (blown voice) and at low frequencies it is mainly due to an irregular vibration of strings, due to their excessive adduction and rigidity. Phonatory attack is irregular (Figures 2(a)-6(a)) and often the presence of diplofony and/or bitonality is indicated on the diagram. However, this is indicative of a subject's 
inability to control individual phono-articulatory productions, a difficulty also explained by the irregular intensity curve (E). This situation is clearly modified in each subject's last spectrographic examination: harmonic texture is now well defined (Figure 2(b), Figure 4(b), Figure 5(b)) and it is not "polluted" by an aperiodic signal (noise) (Figure 2(b), Figures 4(b)-6(b)) and/or sub-harmonics (responsible for diplophony) (Figure 4(b), Figure 6(b)). Individual frequencies $\left(\mathrm{F}_{0}, \mathrm{~F}_{1}\right.$ and $\left.\mathrm{F}_{2}\right)$ are now aligned and phonatory intensity curve $(\mathrm{E})$ has also been normalized (Figures 4(b)-6(b)). In the last exam, phonatory attack is partially or completely presented as a regularized examination (Figures $4(b)-6(b))$ and is now generally soft.

\section{Conflicts of Interest}

The authors declare no conflicts of interest regarding the publication of this paper.

\section{References}

[1] Campanella, A. and Salonna, F. (2012) L'Autogestione Verbo-Vocale (Augev): Metodo educativo per il corretto apprendimento fono-linguistica. Omega edizioni, Torino.

[2] Segre, R. (1976) Normal and Pathological Oral Communication. Edizioni Medico-Scientifiche, Torino.

[3] Kandel, E.R., Schwartz, J.H. and Jassel, T.M. (1999) Neuroscience and Behavior Principles. Casa Editrice Ambrosiana, Milano.

[4] Croatto, L. (1988) Treatise on Phoniatrics and Speech Therapy. Vol. IV: Phoniatric Semeiotics, Voice, Speech, Hearing. La Garangola, Padova.

[5] Schindler, O., Vernero, I., Schinaler, A. and Utari, C. (2000) A Child Who Does Not Speak. Omega Edizioni, Torino.

[6] Njioktjien, C. (2008) Developmental Dyspraxias and Associated Motor Disorders. Edizioni Giuseppe Chiarenza Suy Publications, Amsterdam.

[7] Zerneri, L. (1989) Phoniatric Manual. Edizioni Omega, Torino.

[8] Aronson, A. (1985) Voice Disorders. Masson, Milano.

[9] Croatto, L. (1983) Treatise on Phoniatrics and Speech Therapy. Vol. I: Anatomy and Physiology of Communication Organs. La Garangola, Padova.

[10] Scalise, S. (2002) Giorgio Graffi, "Languages and the Language”. il Mulino, Bologna.

[11] Mininni, G. (2000) "Psychology of Common Speech". Grasso Editore, Bologna.

[12] Piaget, J. (1976) Genesis of Random Ideas in Children. Newton Compton Editori.

[13] Campanella, A. and co., Acta Phoniatrica Latina, Vol. XXIII, n.1— "Proposal for a Re-Educational Method in Subjects with Dysfunctional Dysphonia: Vocal Self-Management”. Edizioni La Garangola, Padova, 2001.

[14] Gialanella, G. (1989) Physics Course. Edizioni Loffredo, Napoli.

[15] Wille, A.M. (1994) A Child of Very Few Words. Psychomotor Therapy and Autism. Editore Marrapese, Roma.

[16] Fussi, M. and De Santis, F. (1993) Words and Songs. Techniques, Problems, Remedies in Voice Professionals. Piccin, Nuova Libraria, Bari. 
[17] Galignano, M. (2013) Pedagogy and Voice Science. Omega Edizioni, Torino.

[18] Fussi, F. and Magnani, S. (2008) Listening to the Voice. A Perceptive Itinerary to Discover Voice Qualities. Ed. Franco Angeli, Milano.

[19] Maturi, P. (2006) Language Sounds, Italian Sounds. il Mulino, Bologna.

[20] Brauner, A. and Dussour, M. (1968) Pre-Reading. Armando-Armando Editore, Roma.

[21] De Colle, W. (2001) Voice and Computer. Edizioni Omega, Torino.

[22] Cohen, M., Lezine, T., Kocher, K. and Brauner, A. (1970) Child's Language. La nuova Italia, Firenze.

[23] Fletcher, P. and Garman, M. (1991) Language Acquisition. Raffaello Cortina Editore, Milano.

[24] Ponzio, A. (2002) Languages and Language. Edizioni B. A. Graphis, Bari.

[25] Croatto, L. (1983) Treatise on Phoniatrics and Speech Therapy. Vol. II: Communication Linguistic Aspects. La Garangola, Padova.

[26] Bonifacio, S. and Stefani, H. (1998) The Communicative and Linguistic Interaction of a Child with Language Delay. Edizioni del Cerro, Pisa.

[27] Bear, M.F., Connors, B.W. and Paradiso, M.A. (2016) Neuroscienze. Esplorando il cervello. Edra edizioni, Milano.

[28] Canevaro, A., Volpi, C. and Laeng, M. (1984) Communication Today: Learning and Its Strategies. Napoli.

[29] American Psychiatric Association (2014) Diagnostic and Statistical Manual of Mental Disorders, 5th Edition, DSM-5TM. Raffaello Cortina Editore, Milano.

[30] Early Diagnosis and Prevention of Language and Communication Disorders. Evaluation Tools. Proceedings of ULI Conference, Corigliano Veneto, 8-10 November 1993.

[31] Piaget, J. (1991) The Birth of Intelligence in the Child. Edizioni Giunti e Barbera, Città di Castello.

[32] Renan, E. (1968) Quotation from Camaioni in "Developmental Psychology".

[33] Metzger, W. (1971) Psychology Fundamentals of Gestalt. Giunti-Barbera, Firenze.

[34] Malim, T. (2000) Cognitive Processes. Attention, Perception, Memory and Thought. Erikson.

[35] Janes, A. (1996) Metacognition and Teaching. Edizioni Erickson, Trento.

[36] Ashman, A.F. (1999) Guide to Metacognitive Teaching. Edizioni Erickson, Trento.

[37] Croatto, L. (1986) Treatise on Phoniatrics and Speech Therapy. Vol. III: Communication Phonetic Aspects. La Garangola, Padova.

[38] Fussi, F. and Magnani, S. (1994) Vocal Art. Edizioni Omega, Torino.

[39] Canepari, L. (1979) Introduction to Phonics. Edizioni Einaudi.

[40] Canepari, L. ()2005 MAPI. Manual of Italian Pronunciation. Edizioni Zanichelli.

[41] Delay, A.J. and Pichot, P. (1965) A Psychology Compendium. Edizioni Giunti, Firenze.

[42] Anastasi, A. (1965) Differential Psychology. Giunti-Barbera, Firenze.

[43] Pettorino, M. (2010) Acoustic Phonetics. Knowledge and Terms of Italian Encyclopedia. Trecccani.

[44] Campanella, A. and co., Acta Phoniatrica Latina, Vol. XXI, No. 4, Disorders of Spatio-Temporal Organization in Subjects with Dysfunctional Dysphonia. Edizioni La 
Garangola, Padova, 1979.

[45] Petter, G. (1971) Vol. I: Psychological Conversations with Teachers. Giunti-Barbera, Firenze.

[46] Schindler, O. (1974) Audiophone-Speech Therapy Manual. Propaedeutics. Omega Edizioni, Torino.

[47] Leoni, F.A. and Maturi, P. (2006) Phonetic Manual. Carocci Editore, Roma.

[48] Campanella, A. (1975) Cooperation between Teacher and Therapist in the Didactic and Rehabilitative Work. Tip. C. Torraco, Bernalda (Mt).

[49] Gilardone, M. and Fussi, F. (1998) Puccini Voices. Edizioni Omega, Torino.

[50] Dal Piai, G. (2008) Diction and Phonetics. Edizioni Fonte alle Grazie, Milano.

[51] Iorio, M. and Milano, M. (1999) Dysphonia. Clinical and Medical-Legal Aspects. Omega Edizioni, Torino. 